\title{
Metabolism and secretion of yellow pigment under high glucose stress with Monascus ruber
}

\author{
Tao Huang ${ }^{1}$, Meihua Wang ${ }^{1}$, Kan Shi ${ }^{1}$, Gong Chen ${ }^{1,2}$, Xiaofei Tian ${ }^{1}$ and Zhenqiang Wu ${ }^{1 *}$ (D)
}

\begin{abstract}
The biosynthesis of microbial secondary metabolites is induced by a wide range of environmental stresses. In this study, submerged fermentation of Monascus yellow pigments by Monascus ruber CGMCC 10910 under high glucose stress was investigated. The increase of lipid content was the major contributor to the increase of dry cell weight (DCW), and the lipid-free DCW was only slightly changed under high glucose stress, which benefited the accumulation of intracellular hydrophobic pigments. The fatty acid composition analysis in Monascus cell membranes showed that high glucose stress significantly increased the ratio of unsaturated/saturated fatty acid and the index of unsaturated fatty acid (IUFA) value, which would improve the fluidity and permeability of the cell membrane. As a consequence, high glucose stress increased extracellular yellow pigments production by enhancing secretion and trans-membrane conversion of intracellular pigments to the broth. The total yield of extracellular and intracellular yellow pigments per unit of lipid-free DCW increased by 94.86 and 26.31\% under high glucose stress compared to conventional fermentation, respectively. A real-time quantitative PCR analysis revealed that the expression of the pigment biosynthetic gene cluster was up-regulated under high glucose stress. The gene $m p p E$, which is associated with yellow pigment biosynthesis, was significantly up-regulated. These results indicated that high glucose stress can shift the Monascus pigment biosynthesis pathway to accumulate yellow pigments and lead to a high yield of both extracellular and intracellular yellow pigments. These findings have potential application in commercial Monascus yellow pigment production.
\end{abstract}

Keywords: Monascus ruber, High glucose stress, Pigments secretion, Gene expression, Yellow pigments, Lipids

\section{Introduction}

Monascus pigments are secondary metabolites with polyketide structures that are produced by Monascus spp. (Feng et al. 2012), and are usually classified by color (yellow, orange or red) (Patakova 2013). Monascus yellow pigments have been widely researched due to their hypolipidemic (Lee et al. 2010), anti-obesity (Lee et al. 2013), anti-inflammation (Hsu et al. 2012), anti-tumor (Su et al. 2005; Lee et al. 2013), anti-diabetic and antioxidative stress (Shi et al. 2012), which are related to the molecular structures of yellow pigments (Su et al. 2005).

\footnotetext{
*Correspondence: btzhqwu@scut.edu.cn

${ }^{1}$ School of Bioscience and Bioengineering, South China University

of Technology, Guangzhou 510006, People's Republic of China

Full list of author information is available at the end of the article
}

It has long been known that the biosynthesis of microbial secondary metabolites is induced by stress (Ranby 1978). Under stress inducing conditions, microorganisms shift from producing primary metabolites to secondary ones in order to preserve energy sources and essential metabolites for more favorable growth conditions. For example, high temperature $\left(>45{ }^{\circ} \mathrm{C}\right)$ can increase the production of Monascus yellow pigments, and a high concentration of sodium chloride inhibited mycelia growth but caused an increase in the production of Monascus red pigments (Babitha et al. 2007). Klebsiella oxytoca fermented with a high concentration of molasses exhibited increased production of 2, 3-butanediol (Afschar et al. 1991). Increased production of monacolin $\mathrm{K}$ was observed when a high 
concentration of glycerol was used as the sole carbon source for Monascus purpureus fermentation with the agricultural residue bagasse used as an inert carrier ( $\mathrm{Lu}$ et al. 2013). In past studies of Monascus pigment fermentation, research has mainly focused on improving cell densities and pigment production in fed-batch cultures with long incubation times (Krairak et al. 2000; Lee et al. 2013; Chen et al. 2015). In fed-batch fermentation of Monascus, compared with low glucose concentration, high glucose concentration had different impact on the production of Monascus pigments (Chen and Johns 1994), and the characteristics of pigments were shifted in Monascus anka fed-batch culture with high cell densities (Chen et al. 2015). Cell membrane is the first barrier of microorganism coping with environmental stress, not only for the nutrients absorption but also for the extracellular products excretion, the absorption and excretion ability of microorganism cell response to the fluidity and permeability of the cell membrane (Zhang and Cheung 2011). Glutamic acid could promote the monacolin $\mathrm{K}$ production by regulating the permeability of Monascus mycelium and then the secretion of monacolin $\mathrm{K}$ was promoted without feedback inhibition from intracellular product (Zhang et al. 2017). The permeability and fluidity of cell membrane depended on the saturability of the containing fatty acid (Wang et al. 2013). As high carbon source but low oxidoreduction potential (ORP) could benefit the production of extracellular water-soluble yellow pigments with Monascus ruber CGMCC 10910 (Wang et al. 2017), multifaceted mechanisms of high glucose stress that had impacted the metabolism and secretion of Monascus yellow pigments should be further investigated.

Recently, the biosynthetic gene cluster of azaphilone pigments in the Monascus pilosus genome and the functions of some critical genes involved in the pigment biosynthetic pathway were reported (Balakrishnan et al. 2013). In the present study, the effect of high glucose stress on the fermentation characteristics of $M$. ruber CGMCC 10910 was investigated. Cell growth and lipid production were analyzed to investigate the relationship between pigment production and lipid metabolism. The fatty acid composition of Monascus cell membrane under high glucose stress was analyzed using GC-MS to study the influence of high glucose stress on the fluidity and permeability of the cell membrane. The expression levels of pigment biosynthetic genes under high glucose stress were measured by real-time quantitative PCR with a simultaneous analysis of extracellular and intracellular pigment compositions. By undertaking these investigations, we hoped that the regulatory mechanisms of pigment metabolism during high glucose stress would be revealed.

\section{Materials and methods}

\section{Microorganism and culture conditions}

All experiments in this study were performed with $M$. ruber CGMCC 10910 (China General Microbiological Culture Collection Center, CGMCC 10910), which was cultivated on PDA medium at $30{ }^{\circ} \mathrm{C}$ for 7 days and then stored at $4{ }^{\circ} \mathrm{C}$. The seed medium contained $(\mathrm{g} / \mathrm{L})$ : glucose, 20; yeast extract, 3; peptone, $10 ; \mathrm{KH}_{2} \mathrm{PO}_{4}, 4 ; \mathrm{KCl}, 0.5$; and $\mathrm{FeSO}_{4} \cdot 7 \mathrm{H}_{2} \mathrm{O}, 0.01$. The inoculum was incubated in a 250 $\mathrm{mL}$ Erlenmeyer flask containing $50 \mathrm{~mL}$ of seed medium at $30{ }^{\circ} \mathrm{C}$ and was shaken at $180 \mathrm{rpm}$ for $25 \mathrm{~h}$. The conventional fermentation medium contained $(\mathrm{g} / \mathrm{L})$ : glucose, 50; $\left(\mathrm{NH}_{4}\right)_{2} \mathrm{SO}_{4}, 5 ; \mathrm{KH}_{2} \mathrm{PO}_{4}, 5 ; \mathrm{MgSO}_{4} \cdot 7 \mathrm{H}_{2} \mathrm{O}, 0.5 ; \mathrm{KCl}, 0.5$; $\mathrm{MnSO}_{4} \cdot \mathrm{H}_{2} \mathrm{O}, 0.03 ; \mathrm{ZnSO}_{4} \cdot 7 \mathrm{H}_{2} \mathrm{O}, 0.01$; and $\mathrm{FeSO}_{4} \cdot 7 \mathrm{H}_{2} \mathrm{O}$, 0.01 . Fermentation medium containing a higher initial glucose concentration (up to $200 \mathrm{~g} / \mathrm{L}$ ) was used for glucose concentration stress experiments. The fermentation experiment was conducted at $30{ }^{\circ} \mathrm{C}$ with shaking at $180 \mathrm{rpm}$ for 8 days in a 250-mL Erlenmeyer flask containing $25 \mathrm{~mL}$ of fermentation media and using $2 \mathrm{~mL}$ of inoculum. All experiments were performed in triplicate.

\section{Measurements of pigment and residual glucose concentration, DCW, lipid weight and lipid-free DCW}

After fermentation, the spent medium was vacuum filtered through a $0.8 \mathrm{~mm}$ mixed cellulose esters membrane, after which the filtrate was diluted. Extracellular pigment production was assessed using a UV-Visible spectrophotometer (Unico, USA) scanning from 300 to $550 \mathrm{~nm}$ at 1-nm intervals (Shi et al. 2015). The absorbance units $(\mathrm{AU})$ at the peak wavelength $(350 \mathrm{~nm}) \mathrm{mul}$ tiplied by the dilution ratio was used as an index of the extracellular yellow pigments concentration (Wang et al. 2017). The residual glucose was determined by the standard 3,5-dinitrosalicylic acid (DNS) method. The mycelia was washed for three times and then dried to a constant weight at $60{ }^{\circ} \mathrm{C}$ to determine biomass (dry cell weight, $\mathrm{DCW}$ ). Some of those dry mycelia were submitted for estimation of lipid content. Lipid content in DCW was determined following the standard method by Bligh and Dyer (1959) with some modifications: $0.2 \mathrm{~g}$ of dry mycelia was re-suspended in $6 \mathrm{~mL}$ hydrochloric acid solution $(4 \mathrm{~mol} / \mathrm{L})$, and then the mixture was heated to $100{ }^{\circ} \mathrm{C}$ and incubated for $3 \mathrm{~min}$. After this, the mixture was immediately cooled down to have the intact cell structure broken down. A $12 \mathrm{~mL}$ of fresh extraction solution (methanol/ chloroform, $1: 1 \mathrm{v} / \mathrm{v}$ ) was added into the cooled mixture and mixed for $30 \mathrm{~s}$. After centrifugation at $5000 \mathrm{rpm}$ for $15 \mathrm{~min}$, the lower (chloroform) phase was collected to a new test tube containing $5 \mathrm{~mL}$ of $0.1 \% \mathrm{NaCl}$ solution. After a centrifugation at $3500 \mathrm{rpm}$ for $5 \mathrm{~min}$, the lower (chloroform) phase was collected and evaporated with flushing nitrogen to get the lipid residual. Then the lipid 
residual was oven dried at $60{ }^{\circ} \mathrm{C}$ to a constant weight to determine the lipid weight. The lipid content was the extracted lipid weight (g) from per $100 \mathrm{~g}$ DCW. The lipidfree DCW was calculated by deducing the lipid weight from the total DCW (Wang et al. 2015a).

The intracellular pigment concentration was determined following those procedure as follows: mycelia were washed and re-suspended in $25 \mathrm{~mL}$ of acidic aqueous ethanol (70\% v/v pH 2 with hydrochloric acid); the mixture was then incubated for $1 \mathrm{~h}$ and then passed through filter paper; finally, the filtrate (intracellular extract) was diluted for determining the intracellular pigment concentration. A UV-Visible absorbance spectrum of intracellular pigments was taken from $300 \mathrm{~nm}$ to $550 \mathrm{~nm}$ at 1-nm intervals, and the absorbance units (AU) at peak wavelengths of 410 and $470 \mathrm{~nm}$ multiplied by the dilution ratio were used as indexes of the intracellular yellow and orange pigments concentrations (Shi et al. 2015), respectively.

\section{Analyses of pigment compositions by HPLC}

Analyses of sample compositions were performed using an Alliance e2695 HPLC system (Waters, Milford, CT, USA) equipped with a 2998 Photodiode Array (PDA) detector (Waters, Milford, CT, USA) and a Zorbax Eclipse Plus C18 column $(250 \times 4.6 \mathrm{~mm}, 5 \mu \mathrm{m}$, Agilent, Palo Alto, CA, USA). The temperature of the column oven was set at $30{ }^{\circ} \mathrm{C}$. A mixture of $\mathrm{H}_{3} \mathrm{PO}_{4}$ solution ( $\mathrm{pH}$ 2.5 , phase $\mathrm{A}$ ) and acetonitrile (phase $\mathrm{B}$ ) were used as the mobile phase using the following gradient program: 0 min, $80 \%$ A, 20\% B; 25 min, 20\% A, 80\% B; 35 min, 20\% A, $80 \%$ B; 36 min, $80 \%$ A, 20\% B; 41 min, $80 \%$ A, 20\% B. The PDA was set at $200-600 \mathrm{~nm}$, and the flow rate of the mobile phase was $0.8 \mathrm{~mL} / \mathrm{min}$.

\section{Analyses of extracellular pigments by LC-MS}

Liquid chromatography-mass spectrometry consisted of a HP1100 HPLC system (Agilent, Palo Alto, CA, USA) and a micro TOF-QII mass spectrometer (Bruker, Rheinstetten, Germany). The C18 column and chromatographic conditions were the same as mentioned above, except for mobile phase A (water, $0.1 \%$ formic acid).

\section{Analysis of cell membrane fatty acid composition by GC- MS}

After 8 days of fermentation, mycelia in the fermentation broth were collected. The fatty acid in cell membrane of the mycelia was extracted, purified and methylated according to the method described by Wang et al. (2013). After that, the sample dissolved in the $n$-hexane was collected for GC-MS analysis, using an Agilent 6890 GC (Agilent, Santa Clara, CA, USA) coupled to an Agilent 5973 mass selective detector (MSD) (Agilent, Santa
Clara, CA, USA), equipped with a HP-5MS column (5\% Phenyl Methyl Silox, $30 \mathrm{~m}-0.25 \mathrm{~mm}$ id $0.25 \mu \mathrm{m}$ film thickness, Agilent, Santa Clara, CA, USA). The front injection was $250{ }^{\circ} \mathrm{C}$ with a split ratio of $70: 1$. Helium gas (purity of $99.9999 \%$, Foshan, China) was used as the carrier gas at a flow rate of $50 \mathrm{~mL} / \mathrm{min}$. The oven temperature program was as follows: $80{ }^{\circ} \mathrm{C}$ for $2 \mathrm{~min}$, then raised to $150{ }^{\circ} \mathrm{C}$ at a rate of $10{ }^{\circ} \mathrm{C} / \mathrm{min}$, and then further to $230{ }^{\circ} \mathrm{C}$ at a rate of $3{ }^{\circ} \mathrm{C} / \mathrm{min}$, keeping at $230{ }^{\circ} \mathrm{C}$ for $5 \mathrm{~min}$. The electron impact energy was $70 \mathrm{eV}$, and the ion source temperature was set at $230{ }^{\circ} \mathrm{C}$.

\section{Gene expression analysis}

The effects of high glucose stress on the expression of key genes during pigments production were investigated using real-time quantitative PCR. Mycelia were collected and stored in liquid $\mathrm{N}_{2}$ before total RNA extraction using the Plant RNA Extraction Kit (TakaRa MiniBEST). cDNA was synthesized using the PrimeScript ${ }^{\mathrm{TM}} \mathrm{RT}$ reagent Kit with gDNA Eraser (TaKaRa). Primers for the amplification of MpFasA2, MpFasB2, MpPKS5, mppR1, mppB, mppC, mppD, mppE, mppR2 (GenBank accession No. KC148521) and the actin gene (GenBank accession No.AJ417880) were listed in Additional file 1: Table S1 according to the previous study (Wang et al. 2015b) with some modifications, actin gene was used as a reference gene. Gene expression was monitored by RT-qPCR using the SYBR Premix Ex TaqII (TaKaRa). RT-qPCR was performed using a Lightcycler 96 (Roche, USA) with the following cycling program: pre-incubation at $95{ }^{\circ} \mathrm{C}$ for $30 \mathrm{~s}$, followed by a two-step amplification (40 cycles of denaturation at $95{ }^{\circ} \mathrm{C}$ for $5 \mathrm{~s}$, and annealing at $60{ }^{\circ} \mathrm{C}$ for $30 \mathrm{~s}$ ) and dissociation curve analyses (at $95^{\circ} \mathrm{C}$ for $10 \mathrm{~s}$, annealing at $65^{\circ} \mathrm{C}$ for $60 \mathrm{~s}$, then collecting dissociation curves from 65 to $95^{\circ} \mathrm{C}$, with a final incubation at $97^{\circ} \mathrm{C}$ for $1 \mathrm{~s}$ ).

\section{Statistical analysis}

Each experiment was repeated at least in triplicate. Numerical data are presented as the mean \pm SD. The differences among different treatments were analyzed using one-way ANOVA. All statistical analyses were performed by using SPSS 22.0, software. $p<0.05, p<0.01$ was considered statistically significant.

\section{Results}

Production of Monascus pigments and lipids during high glucose stress fermentation

The dry cell weight (DCW) of cells takes into account both the accumulation of lipids and lipid-free dry cell weight (LFDCW) accumulation (Wang et al. 2015a). We observed that the final DCW (the sum of lipid weight and LFDCW) increased with an increase in initial glucose concentration (IGC), and that the majority of this DCW 
increase was attributable to an increase of lipid weight at an IGC > $100 \mathrm{~g} / \mathrm{L}$ while LFDCW increased only slightly or even decreased when IGC was up to $200 \mathrm{~g} / \mathrm{L}$ (Fig. 1a). Extracellular yellow pigments production increased sharply with an increased IGC and reached approximately $147 \mathrm{AU}_{350}$ at $150 \mathrm{~g} / \mathrm{L}$ IGC (Fig. 1c), which was approximately twofold higher than when a $50 \mathrm{~g} / \mathrm{L}$ IGC was used. These pigments were mainly water-soluble yellow pigments with a maximum absorption peak at $350 \mathrm{~nm}$. Intracellular yellow pigments also increased with an increasing IGC, but the pigment hue depended on IGC. The maximum absorbance of intracellular pigments was $470 \mathrm{~nm}$ (dominated by orange pigments) under a low IGC $(50 \mathrm{~g} / \mathrm{L})$ but at high IGCs $(>150 \mathrm{~g} / \mathrm{L})$ the maximum absorbance shifted to $410 \mathrm{~nm}$ (dominated by yellow pigments) (Fig. 1d). The ratio of yellow to orange pigments $(\mathrm{Y} / \mathrm{O})$ increased dramatically with an increasing IGC (Fig. 1b).

The increase in DCW was mainly attributable to the increased LFDCW during the first 3 days, while the lipid content started to increase rapidly from the 3rd to 5th day at a low IGC of $50 \mathrm{~g} / \mathrm{L}$ (Fig. 2a). The LFDCW increase extended to the 6th day and the lipid content increased until the 8th day under high glucose stress (Fig. 2b). Extracellular yellow pigments increased with the accumulation of LFDCW and reached a maximum value on the 4th day at which time LFDCW was highest at a low IGC of $50 \mathrm{~g} / \mathrm{L}$ (Fig. 2c). However, during fermentation with high glucose concentrations, extracellular pigments reached maximum productivity on the 6th day when LFDCW was highest (Fig. 2d). This indicated that production of extracellular water-soluble yellow pigments was related to the LFDCW. On the other hand, intracellular pigments (yellow and orange) increased with the accumulation of $\mathrm{DCW}$, reaching a maximum value on the 5th day at which time DCW was highest at an IGC of $50 \mathrm{~g} / \mathrm{L}$. The orange pigments began to decrease from the 5 th day while yellow pigments remained unchanged (Fig. 2c). During high glucose stress, intracellular orange pigments reached the maximum value on the 5 th day and then began to decrease while intracellular yellow pigments increased continuously to the 8 th day (Fig. 2d). The
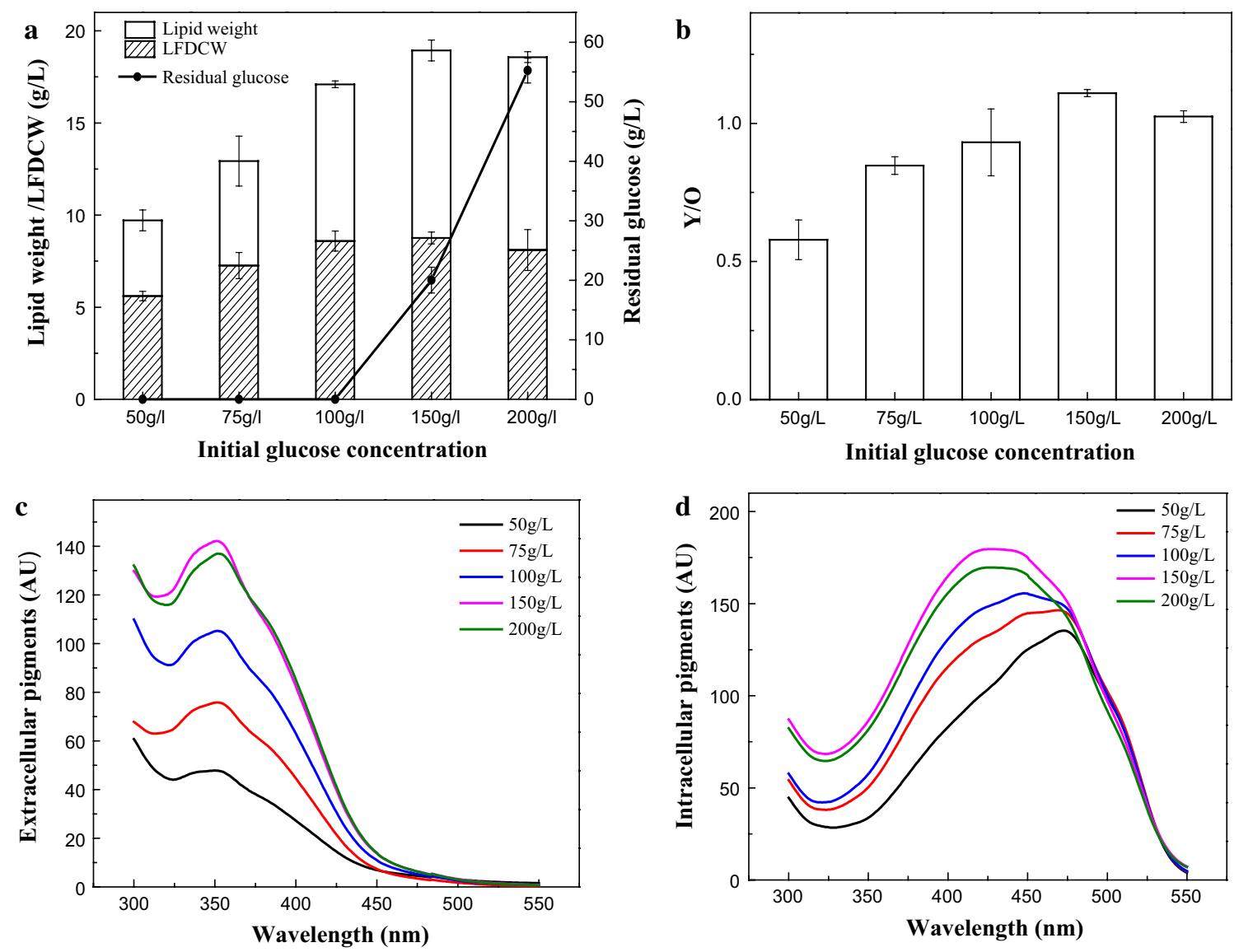

Fig. 1 Metabolism of lipid and pigments with IGC of 50,75, 100, 150 and $200 \mathrm{~g} / \mathrm{L}$. a Lipid weight (g/L), LFDCW (g/L) and residual glucose (g/L). b Ratio of intracellular yellow to orange pigments $(\mathrm{Y} / \mathrm{O}) . \mathbf{c}$ Spectra of extracellular pigments. d Spectra of intracellular pigments 

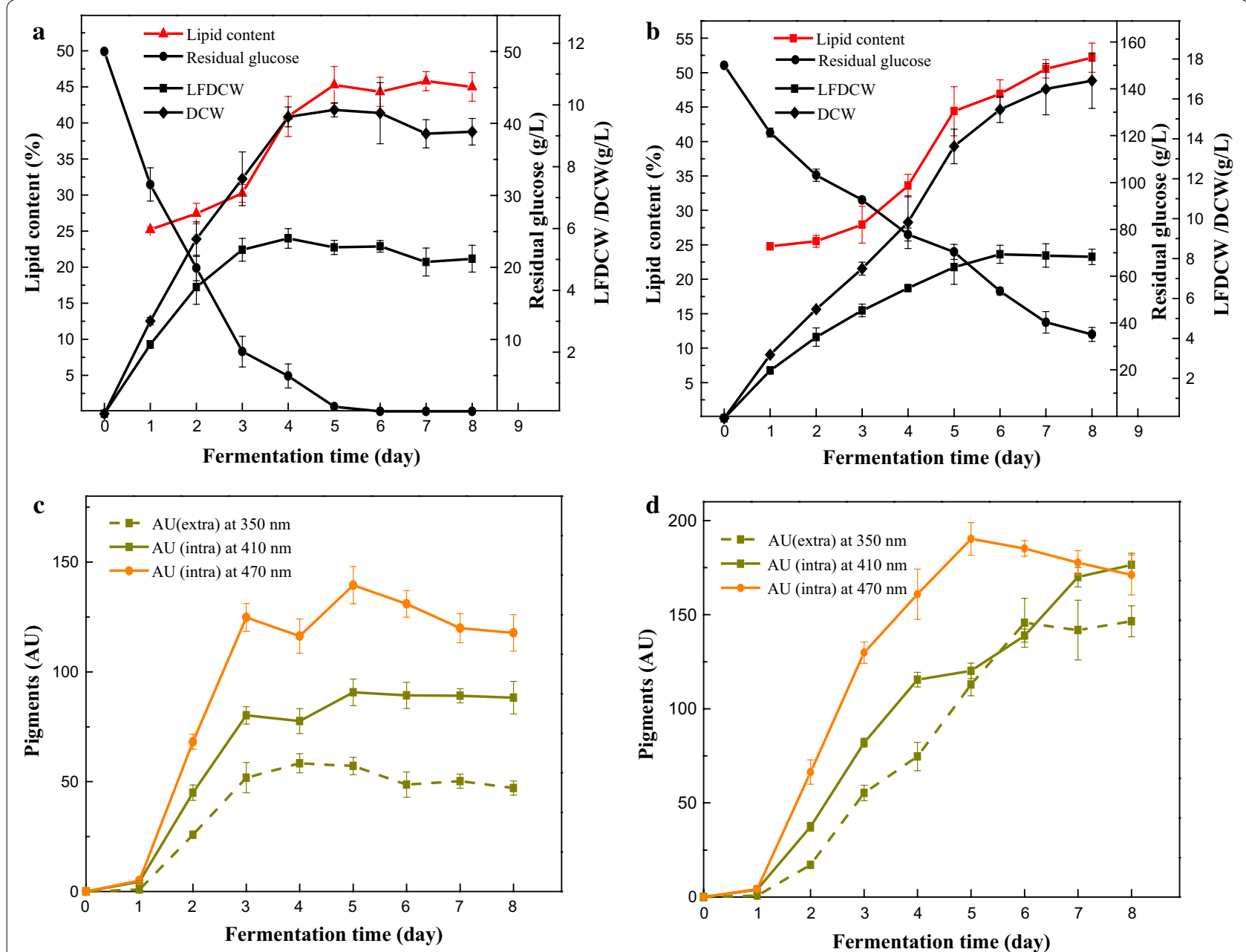

Fig. 2 Time course of lipid content (\%), LFDCW (g/L), DCW (g/L), pigment production and residual glucose (g/L) under different IGCs. a, c $\mathrm{IGC}=50 \mathrm{~g} / \mathrm{L} . \mathbf{b}, \mathbf{d} \mid \mathrm{GC}=150 \mathrm{~g} / \mathrm{L}$

decrease in pigments during the later stage of fermentation indicated the decomposition or transformation from orange pigments into yellow pigments. The production of intracellular pigments was well correlated to cell growth, including both of LFDCW and lipid weight.

Compared to conventional fermentation with $50 \mathrm{~g} / \mathrm{L}$ IGC, the maximum total yields of extracellular and intracellular yellow pigments increased by 194 and $101 \%$, respectively, while the total respective yields of extracellular and intracellular yellow pigments per unit LFDCW improved by 94.86 and $26.31 \%$ and intracellular orange pigments decreased by $10.85 \%$ (Table 1 ) under high glucose stress $(\mathrm{IGC}=150 \mathrm{~g} / \mathrm{L}$ ). Those results demonstrated that a high concentration of glucose benefited the production of yellow pigments, which was due to an increase of DCW and biosynthetic capacity of pigments.

It was worthy to note that four extracellular water-soluble yellow pigments (Y1-Y4) were found in the spent
Table 1 Pigment yield per unit LFDCW and yield increase rate under high glucose stress

\begin{tabular}{|c|c|c|c|}
\hline \multirow[t]{2}{*}{ Pigments } & \multicolumn{3}{|c|}{ Yield (AU per g LFDCW) } \\
\hline & $50 \mathrm{~g} / \mathrm{L}^{\mathrm{a}}$ & $150 \mathrm{~g} / \mathrm{L}^{\mathrm{a}}$ & Increase rate (\%) \\
\hline $\begin{array}{c}\text { Extracellular } \\
\text { yellow }\end{array}$ & $9.326 \pm 0.054$ & $18.173 \pm 0.050$ & 94.86 \\
\hline $\begin{array}{l}\text { Intracellular } \\
\text { yellow }\end{array}$ & $17.376 \pm 0.188$ & $21.947 \pm 0.111$ & 26.31 \\
\hline $\begin{array}{l}\text { Intracellular } \\
\text { orange }\end{array}$ & $23.688 \pm 0.246$ & $21.118 \pm 0.049$ & -10.85 \\
\hline
\end{tabular}

broth (Fig. 3a). Y1 had the UV-Visible spectra with two maximum absorptions at around $225 \mathrm{~nm}$ and $337 \mathrm{~nm}$, Y2 had the UV-Visible spectra with two maximum 
absorptions at around $215 \mathrm{~nm}$ and $361 \mathrm{~nm}, \mathbf{Y 3}$ and Y4 had almost the same UV-Visible spectra with two maximum absorption at around 218, 291 and $388 \mathrm{~nm}$ (Additional file 2: Figure S1). The extracellular broth gave rise to a comprehensive absorption peak at $350 \mathrm{~nm}$. The intracellular pigments were mainly composed of four well-known pigments, including two yellow pigments (monascin and ankaflavin) and two orange pigments (monascorubrin and rubropunctation) but no red pigments (Fig. 3b; Additional file 3: Figure S2). This may have been caused by the use of ammonium sulfate as a nitrogen source that led to a low $\mathrm{pH}(<2.5)$ of the broth, which

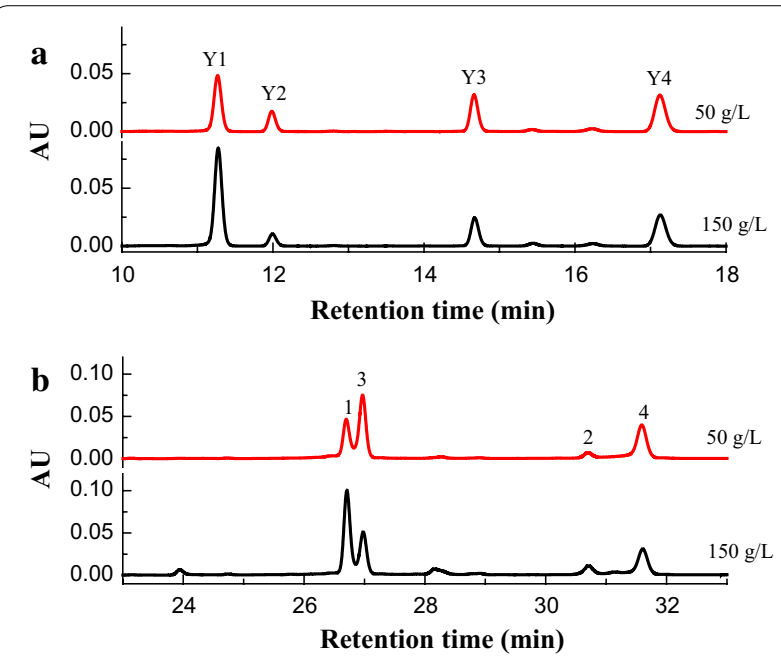

Fig. 3 HPLC-PDA chromatogram of pigments fermented under different IGCS. a Extracellular pigments. b Intracellular pigments. Y1, $\mathrm{Y} 2, \mathrm{Y} 3$ and $\mathrm{Y} 4$ are four extracellular water-soluble yellow pigments. 1 monascin, 2 ankaflavin, 3 rubropunctation, 4 monascorubrin was good for the accumulation of yellow and orange pigments (Shi et al. 2015). In our study, ammonium sulfate used as a sole nitrogen source, resulted in a very low $\mathrm{pH}$ below 2.0. Interestingly, the ratio of intracellular yellow pigments (monascin and ankaflavin) to orange pigments (rubropunctation and monascorubrin) increased under high glucose stress. Under the high glucose stress, yields of the intracellular yellow pigments monascin and ankaflavin, respectively, increased by 94.6 and $51.4 \%$ based on peak areas compared to when a low IGC of $50 \mathrm{~g} / \mathrm{L}$ was used. These results demonstrated that high glucose stress could result in a high proportion of yellow pigments during Monascus cultivation.

\section{Changes of fatty acids composition in cell membrane}

The major fatty acid components in the membrane of $M$. ruber CGMCC 10910 were identified as tetradecanoic acid (C14:0), palmitic acid (C16:0), stearic acid (C18:0), eicosanoic acid (20:0), oleic acid (C18:1), linoleic acid (C18:2) and linolenic acid (C18:3), respectively (Table 2 ). It could be found that the saturated fatty acids, especially stearic acid (C18:0), had a significant decreased but the unsaturated fatty acids, especially oleic acid (C18:1), increased under the high glucose stress $(150 \mathrm{~g} / \mathrm{L})$. The unsaturated/saturated fatty acid ratio and the index of unsaturated fatty acid (IUFA) value increased significantly from 1.520 to 2.028 and from 79.295 to 89.055 , respectively. It was suggested that the $M$. ruber CGMCC 10910 would synthesize more unsaturated fatty acids under high glucose stress which could improve the fluidity and permeability of the cell membrane (Zhang and Cheung 2011; Lyu et al. 2015), and then facilitate transmembrane secretion and conversion of intracellular pigments to the broth (Chen et al. 2017).

Table 2 Fatty acid composition (\% total fatty acid) of cell membranes under high glucose stress

\begin{tabular}{|c|c|c|c|}
\hline \multirow[t]{2}{*}{ Fatty acid composition } & & \multicolumn{2}{|l|}{ IGC (g/L) } \\
\hline & & 50 & 150 \\
\hline \multirow[t]{4}{*}{ Saturated fatty acid } & Tetradecanoic acid (14:0) & $0.123 \pm 0.01$ & $0.157 \pm 0.02$ \\
\hline & Palmitic acid (16:0) & $14.641 \pm 0.22$ & $14.431 \pm 0.18$ \\
\hline & Stearic acid (18:0) & $23.978 \pm 0.56$ & $17.862 \pm 0.47$ \\
\hline & Eicosanoic acid (20:0) & $0.293 \pm 0.03$ & $0.170 \pm 0.01$ \\
\hline \multirow[t]{4}{*}{ Unsaturated fatty acid } & Palmitoleic acid (16:1) & $0.161 \pm 0.02$ & $0.395 \pm 0.05$ \\
\hline & Oleic acid (18:1) & $40.649 \pm 0.86$ & $45.596 \pm 0.78$ \\
\hline & Linoleic acid (18:2) & $17.058 \pm 0.35$ & $17.439 \pm 0.27$ \\
\hline & Linolenic acid (18:3) & $1.457 \pm 0.08$ & $2.730 \pm 0.12$ \\
\hline Unsaturated/saturated ${ }^{\mathrm{a}}$ & & $1.520 \pm 0.01 \mathrm{a}$ & $2.028 \pm 05 \mathrm{~A}$ \\
\hline IUFA (index of unsaturated fatty acid) ${ }^{b}$ & & $79.295 \pm 0.68 b$ & $89.055 \pm 0.54 B$ \\
\hline
\end{tabular}

Data are mean \pm standard deviation $(n=3)$. Means in a row with different lowercase/capital letters are significantly different $(p<0.05)$

${ }^{a}(C 18: 1+\mathrm{C} 18: 2+\mathrm{C} 18: 3) /(C 14: 0+\mathrm{C} 16: 0+\mathrm{C} 17: 0+\mathrm{C} 18: 0+\mathrm{C} 20: 0)$

b $(\mathrm{C} 18: 1)+(\mathrm{C} 18: 2) \times 2+(\mathrm{C} 18: 3) \times 3$ 


\section{Expression levels of pigment biosynthetic genes}

The expression levels of the pigment biosynthetic genes MpFasA2, MpFasB2, MpPKS5, mppB, mppC, mppD, $m p p E$, mppR1 and $m p p R 2$ during the fermentation course under high glucose stress (IGC $=150 \mathrm{~g} / \mathrm{L}$ ) were monitored by RT-qPCR (Fig. 4). Gene expression test samples corresponded one-to-one with the samples used for pigments testing. Transcriptional levels were normalized to that of the actin gene. To standardize the results, we took the mRNA levels accumulated during the 2nd day of the control (IGC $=50 \mathrm{~g} / \mathrm{L}$ ) as the reference value (value 1). The expression levels of the pigment biosynthetic genes first increased, and then decreased during the fermentation under high glucose stress. During the first 3 days, the expression levels of the genes $m p p E$, $m p p D$ and regulatory gene $m p p R 2$ were significantly upregulated under the high glucose stress. In the middle and later stages of the fermentation (from the 3rd day to the 8th day), the expression levels of the genes $M p F a s A 2$, MpFasB2, MpPKS5, mppB, mppD, mppE, and mppR1 were significantly up-regulated $(p<0.01$ or $p<0.05)$ and they were all higher than the control. But the expression levels of the gene $m p p C$ and the regulatory gene $m p p R 2$ were down-regulated. These results demonstrated that high glucose stress could regulate gene expression for pigment biosynthesis, and increase production of both intracellular and extracellular pigments (Fig. 1).

During the fermentation anaphase (after the 6th day), the expression levels of MpFasA2, MpFasB2, MpPKS5, $m p p D, m m p B$, and $m p p R 1$ were significantly up-regulated $(p<0.01$ or $p<0.05)$. As the genes MpFasA2, $M p F a s B 2, M p P K S 5, m p p D$, and $m p p B$ are structural genes for pigment biosynthesis and $m p p R 1$ is a regulatory gene (Balakrishnan et al. 2013), the polyketide chromophores and media fatty acid were still being generated during fermentation anaphase under high glucose stress. Simultaneously, the gene $m p p E$ for yellow pigment biosynthesis (Balakrishnan et al. 2017) was significantly up-regulated, while the gene $m p p C$ for orange pigment biosynthesis (Liu et al. 2014) was down-regulated in

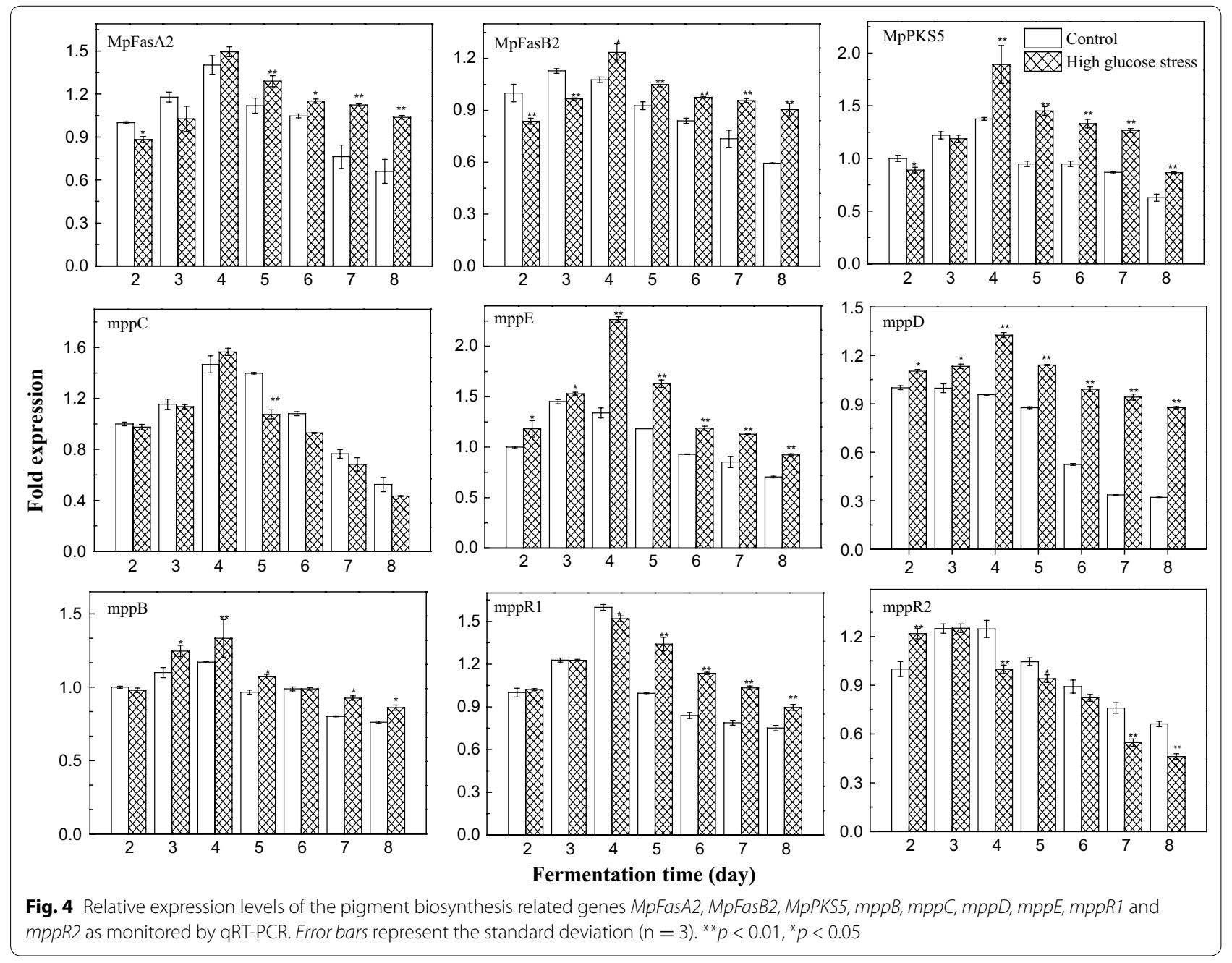


some degree. In combination with the time course of pigment production, the up-regulation of $m p p E$ was positively correlated with the production of yellow pigments in the later stages of fermentation.

\section{Discussion}

Monascus pigments are mixtures with multi-components (Juzlova et al. 1996; Patakova 2013). The concentration of Monascus pigments is usually represented by the absorbance at their characteristic wavelength (Babitha et al. 2007). Thus, the pigments yield in this study was represented by the absorbance at their characteristic wavelength (350, 410, and $470 \mathrm{~nm}$ ). Submerged fermentation of Monascus species with a low IGC in the medium resulted in the accumulation of intracellular orange Monascus pigments exhibiting a peak at $470 \mathrm{~nm}$ (Kang et al. 2014). In this study, high yields of both extracellular and intracellular yellow pigments were obtained using $M$. ruber CGMCC 10910 when the IGC were increased from $50 \mathrm{~g} / \mathrm{L}$ (low) to $>150 \mathrm{~g} / \mathrm{L}$ (high). An interesting phenomenon was observed that the dominating intracellular pigments changed from orange to yellow pigments (Fig. 1). In the later stage of fermentation under high glucose stress, the accumulation of DCW was mostly attributable to the increased intracellular lipid weight as the LFDCW was only slightly changed when the IGC was higher than $100 \mathrm{~g} / \mathrm{L}$. When the IGC was $150 \mathrm{~g} / \mathrm{L}$, the lipid weight reached approximately $53 \%$ of the DCW, $20 \%$ higher than what was observed at a low glucose concentration (IGC $=50 \mathrm{~g} / \mathrm{L})$. It has been reported that Monascus purpureus albino strain accumulated a high content of lipids under a limited nitrogen condition (carbon to nitrogen $=80: 1)$ (Rasheva et al. 1997). The high lipid production observed in this study was also caused by a high ratio of carbon to nitrogen in the media. Lipid droplets in living microorganisms could serve as a reservoir for intracellular Monascus pigments, and there was a positive correlation between intracellular pigments and microbial lipids (Wang et al. 2015a). The intracellular yellow pigments and lipid content all increased continuously to the 8th day under high glucose stress (Fig. 2), the reason was that the intracellular lipids act as reservoirs for intracellular yellow pigments storage. Thus, high glucose stress increased the content of Monascus mycelia mainly by increasing the lipids content of Monascus mycelia, which can improve more reservoirs for intracellular yellow pigments storage (Wang et al. 2015a), thus enhancing intracellular yellow pigments production.

Except for extractive fermentation, most of Monascus pigment studies focused on the intracellular pigments biosynthesis (Balakrishnan et al. 2013, 2014, 2017; Bijinu et al. 2014), while only a small amount of research had been done on the biosynthesis pathway of extracellular pigments (Koehler 1983; Hajjaj et al. 1997). Hajjaj et al. (1997) discovered that Monascus could produce the extracellular red pigments $\mathrm{N}$-glucosylrubropunctamine and $\mathrm{N}$-glucosylmonascorubramine in a chemically defined culture medium with excess glucose and monosodium glutamate (nitrogen source). Chen et al. (2017) found that the intracellular orange pigments could be converted to extracellular yellow pigments during the trans-membrane secretion process in a nonionic surfactant aqueous solution (Chen et al. 2017). So, we speculated that the extracellular water-soluble yellow pigments in this study were derivatives of intracellular pigments via the trans-membrane conversion. The pigments were further identified by means of LC-MS (Additional file 4: Figure S3). Based on their UV-Visible spectra (Additional file 2: Figure S1) and molecular weights, It could be deduced that the four pigments have not been described and reported before (Chen and Wu 2016). It needed to be confirmed by identifying the structure of four extracellular water-soluble yellow pigments further. We could also observe that the production of extracellular water-soluble yellow pigments were growth-associated and were coupled to LFDCW, while the concentration of intracellular pigments was just partially associated with cell growth (Fig. 2). A possible reason for this is that during the earlier stages of fermentation, the increased of DCW was mainly attributable to the increasing LFDCW and lower intracellular lipid accumulated, resulting in fewer reservoirs for intracellular pigment storage. The time accumulated LFDCW was extended under a high IGC (Fig. 2b), which allowed more time for the biosynthesis and secretion of derivative extracellular pigments (water-soluble yellow pigments). During the later stages of the fermentation, the increased DCW was mainly due to increased lipids (Fig. 2b), which may have served as reservoirs for accumulating intracellular pigments and caused less pigments precursors to be available for the conversion and secretion of extracellular water-soluble yellow pigments (Fig. 2d). On the other hand, the high glucose stress could also promote the biosynthesis of unsaturated fatty acids in $M$. ruber and make a better fluidity and permeability of the cell membrane, which would improve the trans-membrane conversion and secretion of intracellular pigments to the broth. The similar report could be found that the fumaric acid production could be improved under high glucose stress through synthesizing more unsaturated fatty acids than the saturated one to alternate the fluidity and permeability of the cell membrane with Rhizopus oryzae (Lyu et al. 2015). High glucose stress changed the permeability of Monascus mycelia, enhanced the transmembrane conversion and secretion of intracellular pigments to the broth, and improved the production of extracellular yellow pigments. 
The biosynthesis of Monascus pigments follows the polyketide pathway (Hajjaj et al. 1997; Shao et al. 2014). MpPKS5 and mppD are the structural genes of Monascus pigments and encode the polyketide synthases which are keys to the biosynthesis the polyketide chromophore of these pigments. The genes MpfasA2 and MpfasB2 (Mpfas2) encode a canonical fungal fatty acid synthase and supply the medium-chain (C8 and C10) fatty acyl moieties for Monascus pigments biosynthetic activities (Balakrishnan et al.2013, 2014). The $m p p B$ gene encodes a trichothecene 3-O-acetyltransferase (AT), which can transfer the medium-chain (C8 and C10) fatty acyl group into the polyketide chromophore to complete pigment biosynthesis. The $m p p R 1$ and $m p p R 2$ genes are regulatory genes for pigments biosynthesis (Balakrishnan et al. 2013). The genes MpPKS5, MpfasA2, MpfasB2, mppB, $m p p R 1$, and $m p p D$ were up-regulated during high glucose stress in the later stage of fermentation (Fig. 4). Furthermore, the increased glucose as the sole carbon source could offer more precursors and cofactors such as acetyl$\mathrm{CoA}$, malonyl-CoA, NADH and NADPH for the biosynthesis of Monascus pigments and lipids (Beatriz Ruiz et al. 2010). These results illustrated that the polyketide biosynthesis capacity could be enhanced by increasing the polyketide chromophores, medium-chain fatty acyl moieties and critical polyketide synthases under high glucose stress. It helped support that high glucose stress promoted the production of yellow pigments through an internal power and the promoting effect is stable.

The gene $m p p E$ encodes a reductive enzyme which controls the biosynthesis of the yellow pigments (ankaflavin and monascin) in the polyketide biosynthesis pathway. The production of orange pigment was enhanced, while that of the yellow pigments decreased in an $m p p E$ knockout mutant $(\triangle m p p E)$. The production of yellow pigments was only enhanced with marked reductions in other pigments in an $m p p E$ overexpression strain $(O V-m p p E)$ (Balakrishnan et al. 2017). Up-regulation of $m p p E$ occurred during an increase in yellow pigments (ankaflavin and monascin) and a decrease in orange pigments under blue light stimulation (Chen et al. 2016). The $m p p C$ gene also encodes an oxidoreductase that shares a $98 \%$ consensus of amino acid sequence with MpigE in Monascus ruber M7. The MpigE deletion strain ( $\triangle M p i g E)$ just yielded four

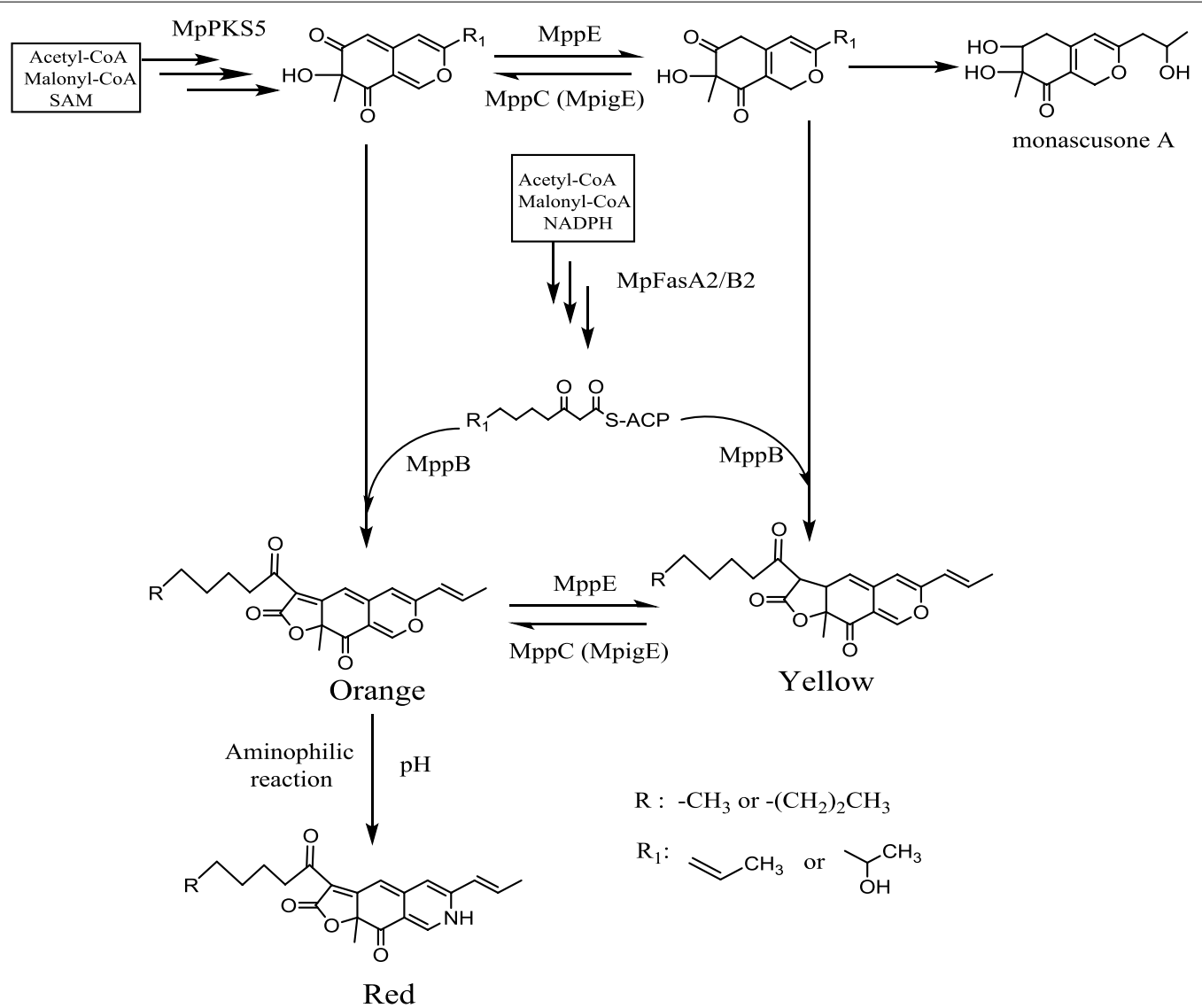

Fig. 5 Putative biosynthetic pathway of Monascus pigments 
kinds of yellow pigments but was very limited in red pigments, whereas production of orange and red Monascus pigments was recovered by MpigE complementation strain ( $\triangle$ MpigE::MpigE) (Liu et al. 2014). The orange pigments monascorubrin and rubropunctatin could be reduced to the yellow pigments ankaflavin and monascin, respectively (Hajjaj et al. 2000). In this study, high glucose stress up-regulated the relative expression level of the gene $m p p E$ while down-regulated the gene $m p p C$ and $m p p R 2$ (Fig. 4), which increased more reductive enzymes involved in yellow pigment biosynthesis (Balakrishnan et al. 2017). In addition, high concentration of glucose could provide high reducing power (NADH or NADPH) (Beatriz Ruiz et al. 2010). As a consequence, the intracellular yellow pigments (monascin and ankaflavin) dramatically increased in the later stages of fermentation while intracellular orange pigments decreased to some degree under high glucose stress (Figs. 2d, 3), and resulted in a high yield of yellow pigments. In light of these results, a putative biosynthetic pathway of Monascus pigments was shown in Fig. 5, which includes the chemical modification of orange pigments to generate red ones through an aminophilic reaction between orange Monascus pigments and primary amine (Jung et al. 2003; Xiong et al. 2015; Shi et al. 2016). In which there may be some oxidoreduction conversion of the polyketide chromophores between yellow and orange pigments or a direct conversion between yellow and orange pigments. The genes $m p p E$ and MpigE ( $m p p C$ ) may all be involved in this conversion (Fig. 5).

In summary, high glucose stress improved more reservoirs for intracellular pigments storage by increasing the content of Monascus mycelia and the lipids content in Monascus mycelia. Simultaneously, high glucose stress up-regulated the expression of pigment biosynthetic genes, especially the genes involved in yellow pigments biosynthetic. Thereby, a high proportion of intracellular yellow pigments rather than orange pigments were achieved under high glucose stress. High glucose stress also improved the fluidity and permeability of the cell membrane and enhanced the trans-membrane conversion of intracellular pigments to extracellular water-soluble yellow pigments and secretion into the broth, resulted in a twofold increase of extracellular water-soluble yellow pigments compared to low IGC condition. Further studies are needed to elucidate the molecular pathways through which high glucose stress regulates yellow pigments production. Thus, submerged fermentation under high glucose stress has potential application in the production of Monascus yellow pigments.

\section{Additional files}

Additional file 1: Table S1. Primers used for RT-qPCR analyzing pigment biosynthesis genes.

Additional file 2: Figure S1. UV-Visible spectra of extracellular pigments detected by HPLC-PDA.

Additional file 3: Figure S2. UV-Visible spectra of intracellular pigments detected by HPLC-PDA.

Additional file 4: Figure S3. LC-MS analysis of extracellular pigments. a Total ion chromatograms, absorption traces of the pigments. Y1-Y4, Mass spectra and their collision-induced fragmented data.

\begin{abstract}
Abbreviations
HPLC: high performance liquid chromatography; DCW: dry cell weight; LFDCW: lipid-free dry cell weight; RT-qPCR: real-time quantitative PCR; GC-MS: gas chromatograph-mass spectrometer; LC-MS: liquid chromatograph-mass spectrometer.
\end{abstract}

\section{Authors' contributions}

$\mathrm{TH}$ planned and carried out the experiments, analyzed the data and wrote the manuscript; MHW, KS and GC assisted to carry out experiments; XFT reviewed the manuscript; ZQW participated in the data analysis and finalized the manuscript. All authors read and approved the final manuscript.

\section{Author details \\ ${ }^{1}$ School of Bioscience and Bioengineering, South China University of Tech- nology, Guangzhou 510006, People's Republic of China. ${ }^{2}$ Dongguan Tianyi Biotech. Co.Ltd., Dongguan 523000, People's Republic of China.}

\section{Acknowledgements}

This study was supported by the financial support of the National Natural Science Foundation of China (No: 31271925), the Special Project on the Integration of Industry, Education and Research of Guangdong Province, China (No: 2013B090600015) and the Science and Technology Program of Guangzhou, China (No: 2014J410019).

\section{Competing interests}

The authors declare that they have no competing interests.

\section{Availability of data and materials}

We conducted experiments and data generated. All data is shown in figures, tables and Additional files 1, 2, 3 and 4 .

\section{Ethics approval and consent to participate}

Not applicable. This article does not contain any studies with human participants or animals performed by any of the authors.

\section{Funding}

This study were funded by the financial support of the National Natural Science Foundation of China (No: 31271925), the Special Project on the Integration of Industry, Education and Research of Guangdong Province, China (No: 2013B090600015) and the Science and Technology Program of Guangzhou, China (No: 2014J410019).

\section{Publisher's Note}

Springer Nature remains neutral with regard to jurisdictional claims in published maps and institutional affiliations.

Received: 29 March 2017 Accepted: 3 April 2017

Published online: 11 April 2017 


\section{References}

Afschar AS, Bellgardt KH, Rossell C, Czok A, Schaller K (1991) The production of 2,3-butanediol by fermentation of high test molasses. Appl Microbiol Biotechnol 34:582-585

Babitha S, Soccol CR, Pandey A (2007) Effect of stress on growth, pigment production and morphology of Monascus sp. in solid cultures. J Basic Microbiol 47:118-126

Balakrishnan B, Karki S, Chiu S, Kim H, Suh J, Nam B, Yoo Y, Chen C, Kwon H (2013) Genetic localization and in vivo characterization of a Monascus azaphilone pigment biosynthetic gene cluster. Appl Microbiol Biotechnol 97:6337-6345

Balakrishnan B, Kim H, Suh J, Chen C, Liu K, Park S, Kwon H (2014) Monascus azaphilone pigment biosynthesis employs a dedicated fatty acid synthase for short chain fatty acyl moieties. J Korean Soc Appl Bi 57:191-196

Balakrishnan B, Park S, Kwon H (2017) A reductase gene mppE controls yellow component production in azaphilone polyketide pathway of Monascus. Biotechnol Lett 39:163-169

Beatriz Ruiz ACAF, Sánchez DRBS, Sergio Sánchez E, Langley E (2010) Production of microbial secondary metabolites: regulation by the carbon source. Crit Rev Microbiol 2:146-167

Bijinu B, Suh J, Park S, Kwon H (2014) Delineating Monascus azaphilone pigment biosynthesis: oxidoreductive modifications determine the ring cyclization pattern in azaphilone biosynthesis. RSC Adv 4:59405-59408

Bligh GE, Dyer JW (1959) A rapid method for total lipid extraction and purification. Can J Biochem Physiol 37:911-917

Chen MH, Johns MR (1994) Effect of carbon source on ethanol and pigment production by Monascus purpureus. Enzyme Microb Technol 16:584-590

Chen G, Wu Z (2016) Production and biological activities of yellow pigments from Monascus fungi. World J Microbiol Biotechnol 32:1-8

Chen G, Shi K, Song D, Quan L, Wu Z (2015) The pigment characteristics and productivity shifting in high cell density culture of Monascus anka mycelia. BMC Biotechnol 15:72

Chen D, Xue C, Chen M, Wu S, Li Z, Wang C (2016) Effects of blue light on pigment biosynthesis of Monascus. J Microbiol 54:305-310

Chen G, Bei Q, Shi K, Tian X, Wu Z (2017) Saturation effect and transmembrane conversion of Monascus pigment in nonionic surfactant aqueous solution. AMB Expr 7:24

Feng Y, Shao Y, Chen F (2012) Monascus pigments. Appl Microbiol Biotechnol 96:1421-1440

Hajjaj H, Klaebe A, Loret MO, Tzedakis T, Goma G, Blanc PJ (1997) Production and identification of $\mathrm{N}$-glucosylrubropunctamine and $\mathrm{N}$-glucosylmonascorubramine from Monascus ruber and occurrence of electron donoracceptor complexes in these red pigments. Appl Environ Microbiol 63:2671-2678

Hajjaj H, Blanc P, Groussac E, Uribelarrea JL, Goma G (2000) Kinetic analysis of red pigment and citrinin production by Monascus ruber as a function of organic acid accumulation. Enzyme Microb Technol 27:619-625

Hsu Y, Lee B, Liao T (2012) Monascus fermented metabolite monascin suppresses inflammation via PPAR- $\gamma$ regulation and JNK inactivation in THP-1 monocytes. Food Chem Toxicol 50:1178-1186

Jung H, Kim C, Kim K, Shin CS (2003) Color characteristics of Monascus pigments derived by fermentation with various amino acids. J Agric Food Chem 51:1302-1306

Juzlova P, Marfinkova L, Kren V (1996) Secondary metabolites of the fungus Monascus: a review. J Ind Microbiol Biotechnol 16:163-170

Kang B, Zhang X, Wu Z, Wang Z, Park S (2014) Production of citrinin-free Monascus pigments by submerged culture at low pH. Enzyme Microb Technol 55:50-57

Koehler HWAP (1983) Production of red water-soluble Monascus pigments. J Food Science 48:1200-1203

Krairak S, Yamamura K, Irie R, Nakajima M, Shimizu H (2000) Maximizing yellow pigment production in fed-batch culture of Monascus sp. J Biosci Bioeng 90:363-367

Lee C, Kung Y, Wu C, Hsu Y, Pan T (2010) Monascin and ankaflavin act as novel hypolipidemic and high-density lipoprotein cholesterol-raising agents in red mold Dioscorea. J Agric Food Chem 58:9013-9019

Lee C, Wen J, Hsu Y (2013) Monascus-fermented yellow pigments monascin and ankaflavin showed antiobesity effect via the suppression of differentiation and lipogenesis in obese rats fed a high-fat diet. J Agric Food Chem 61:1493-1500
Liu Q, Xie N, He Y, Wang L, Shao Y, Zhao H, Chen F (2014) MpigE, a gene involved in pigment biosynthesis in Monascus ruber M7. Appl Microbiol Biotechnol 98:285-296

Lu L, Zhang B, Xu G (2013) Efficient conversion of high concentration of glycerol to Monacolin K by solid-state fermentation of Monascus purpureus using bagasse as carrier. Bioproc Biosyst Eng 36:293-299

Lyu C, Xu Q, Jiao C, Li S (2015) Physiological characteristics of a high-glucose resistant Rhizopus oryzae. Chinese J Bioproc Eng 13:36-40

Patakova P (2013) Monascus secondary metabolites: production and biological activity. J Ind Microbiol Biotechnol 40:169-181

Ranby BARJ (1978) Singlet oxygen. Wiley, Chichester

Rasheva T, Kujumdzieva A, Hallet JN (1997) Lipid production by Monascus purpureus albino strain. J Biotechnol 56:217-224

Shao Y, Lei M, Mao Z, Zhou Y, Chen F (2014) Insights into Monascus biology at the genetic level. Appl Microbiol Biotechnol 98:3911-3922

Shi Y, Liao VH, Pan T (2012) Monascin from red mold dioscorea as a novel antidiabetic and antioxidative stress agent in rats and. Free Radic Biol Med 52:109-117

Shi K, Song D, Chen G, Pistolozzi M, Wu Z, Quan L (2015) Controlling composition and color characteristics of Monascus pigments by $\mathrm{pH}$ and nitrogen sources in submerged fermentation. J Biosci Bioeng 120:145-154

Shi K, Chen G, Pistolozzi M, Xia F, Wu Z (2016) Improved analysis of Monascus pigments based on their pH-sensitive Uv-Vis absorption and reactivity properties. Food Addit Contam 33:1396-1401

Su N, Lin Y, Lee M, Ho C (2005) Ankaflavin from Monascus-Fermented red rice exhibits selective cytotoxic effect and induces cell death on Hep G2 cells. J Agric Food Chem 53:1949-1954

Wang Y, Zhang B, Lu L, Huang Y, Xu G (2013) Enhanced production of pigments by addition of surfactants in submerged fermentation of Monascus purpureu H1 102. J Sci Food Agric 93:3339-3344

Wang B, Zhang X, Wu Z, Wang Z (2015a) Investigation of relationship between lipid and Monascus pigment accumulation by extractive fermentation. J Biotechnol 212:167-173

Wang C, Chen D, Chen M, Wang Y, Li Z, Li F (2015b) Stimulatory effects of blue light on the growth, monascin and ankaflavin production in Monascus. Biotechnol Lett 37:1043-1048

Wang M, Huang T, Chen G, Wu Z (2017) Production of water-soluble yellow pigments via high glucose stress fermentation of Monascus ruber CGMCC 10910. Appl Microbiol Biotechnol: 1-10

Xiong X, Zhang X, Wu Z, Wang Z (2015) Coupled aminophilic reaction and directed metabolic channeling to red Monascus pigments by extractive fermentation in nonionic surfactant micelle aqueous solution. Process Biochem 50:180-187

Zhang B, Cheung PCK (2011) A mechanistic study of the enhancing effect of Tween 80 on the mycelial growth and exopolysaccharide production by Pleurotus tuber-regium. Bioresour Technol 102:8323-8326

Zhang C, Liang J, Yang L, Chai S, Zhang C, Sun B, Wang C (2017) Glutamic acid promotes monacolin $\mathrm{K}$ production and monacolin $\mathrm{K}$ biosynthetic gene cluster expression in Monascus. AMB Expr 7:22

\section{Submit your manuscript to a SpringerOpen ${ }^{\odot}$ journal and benefit from:}

- Convenient online submission

- Rigorous peer review

- Immediate publication on acceptance

- Open access: articles freely available online

- High visibility within the field

- Retaining the copyright to your article

Submit your next manuscript at $>$ springeropen.com 